\title{
Conformidade normativa dos estabelecimentos de educação infantil privados de Gravataí, RS
}

\section{Regulatory compliance of private establishments for early childhood education in the city of Gravataí, RS}

Suelen Cavalheiro Teixeira',* (DD

Patrícia Silva da Silva' (iD

Ronaldo Bordin" (i)
Secretaria Municipal de Saúde, Gravataí, RS, Brasil

" Programa de Pós-Graduação em Administração, Universidade Federal do Rio Grande do Sul, Porto Alegre, RS, Brasil

\section{* E-mail: sucavalheiro82@gmail.com}

\section{RESUMO}

Introdução: No estado do Rio Grande do Sul, a Portaria Estadual n 172, de 3 de maio de 2005, estabelece o regulamento técnico para licenciamento de Estabelecimentos de Educação Infantil (zero-seis anos), incluindo: aspectos relacionados com higiene, conservação e organização dos ambientes, móveis e utensílios; profissionais mínimos necessários presentes no quadro funcional; a necessidade de um projeto arquitetônico aprovado na Vigilância Sanitária municipal; autorização de funcionamento expedida pelo Conselho Estadual ou Municipal de Educação, entre outros. Objetivo: Descrever a conformidade normativa dos Estabelecimentos de Educação Infantil privados existentes no município de Gravataí (Rio Grande do Sul), no período de janeiro de 2018 a abril de 2019. Método: Foram empregados como fonte de dados os documentos exigidos para regularização dos estabelecimentos junto à Vigilância Sanitária e à Secretaria Municipal de Educação. Resultados: Dos 69 estabelecimentos registados no período, quatro foram interditados pela Vigilância Sanitária, cinco encerraram as atividades e 60 permaneciam ativos. Entre os 60 estabelecimentos ativos, oito possuíam alvará sanitário vigente, 20 possuíam projeto arquitetônico aprovado na Vigilância Sanitária municipal, 36 estabelecimentos possuíam documentação mínima e aprovação pelo Conselho Municipal de Educação de Gravataí e 13 contavam com professores devidamente habilitados. Conclusões: A maioria dos estabelecimentos não preenchia os requisitos presentes na Portaria Estadual que regulamenta o licenciamento de funcionamento dos mesmos.

PALAVRAS-CHAVE: Educação Infantil; Vigilância em Saúde; Gestão em Saúde; Administração Pública

\begin{abstract}
Introduction: In the state of Rio Grande do Sul, State Ordinance number 172/2005 establishes the technical regulation for licensing of preschool education (0-6 years old), including: aspects related to hygiene, conservation and organization of environments, furniture and utensils; minimum required professionals present in the staff; the need for an approved architectural project in municipal sanitary surveillance and operating authorization issued by the State or Municipal Board of Education, among others. Objective: To describe the regulatory compliance of private establishments for early childhood education in the city of Gravataí (RS), from January 2018 to April 2019. Method: The documents required to regularize the establishments with the Health Surveillance and the Municipal Department of Education were used as data source. Results: Of the 69 establishments registered in the period, 4 were banned by the Sanitary Surveillance, 5 closed its activities and 60 remained active. Among the 60 active establishments, 8 had a current sanitary permit, 20 had an architectural project approved by the municipal sanitary surveillance, 36 had minimum documentation and approval by the Gravataí Municipal Education Council and 13 relied on properly qualified teachers. Conclusions: Most establishments did not meet the requirements of the Ordinance that regulates their licensing.
\end{abstract}

KEYWORDS: Early Childhood Education; Public Health Surveillance; Health Management; Public Administration 


\section{INTRODUÇÃO}

Desde o século XIX, na Europa já existiam instituições de educação infantil, conhecidas como creches, escolas maternais ou jardins de infância, que visavam a valorização dos brinquedos e do ato de brincar. No Brasil, estas instituições apareceram após a Lei do Ventre Livre (1871), visto que a mulher trabalhadora necessitava deixar seus filhos em um local durante a sua jornada laboral, e apresentavam um caráter assistencialista com foco no cuidado das crianças ${ }^{1,2,3}$.

Até 1960, o sistema educacional brasileiro era centralizado no âmbito federal. A primeira Lei de Diretrizes e Bases da Educação (LDB), de 1961, trouxe a descentralização de competências aos órgãos estaduais e municipais. No entanto, a inclusão efetiva da educação infantil se deu quase três décadas após, com a Constituição Federal (CF) de 1988 e a LDB n 9.394, de 20 de dezembro de 1996, que revogou a anterior ${ }^{4}$. Atualizada no ano de 2018, a LDB garante a educação desde o ensino infantil até o superior, considera a educação infantil como etapa da educação básica e determina a competência dos estados e municípios na organização de suas ações ${ }^{5}$.

Na CF de 1988, a educação das crianças de zero a seis anos, entendida até aquele momento como amparo e assistência, tornou-se direito do cidadão e dever do Estado, com a proteção integral às crianças devendo ser assegurada pela família, sociedade e poder público. A inclusão da creche no capítulo da educação explicitou a função educativa desta, sem esquecer a função primordial do cuidar ${ }^{6}$.

A função da educação básica é assegurar uma formação integral, indispensável ao educando, desenvolvendo-o para o convívio em sociedade e preparando-o para as etapas seguintes, como os ensinos fundamental e médio. A educação básica objetiva a redução das desigualdades sociais por intermédio dos princípios da equidade, da valorização da diversidade e direitos humanos ${ }^{3,4}$. Em consonância, a Política Nacional da Educação Infantil, de 2003, visa a implementação de programas para crianças na faixa etária de zero a seis anos, a garantia e o desenvolvimento integral do educando no ambiente escolar, de forma complementar ao ambiente familiar. Além disso, foi inserida em uma de suas diretrizes a articulação com outras secretarias, incluindo a Saúde ${ }^{3}$.

Com o avanço da educação infantil no Brasil, surgiu a necessidade de regulamentar esta atividade, bem como a estrutura física dos estabelecimentos. Desta forma, o Ministério da Saúde (MS) definiu padrões mínimos para normatizar a construção, a instalação e o funcionamento de creches. Contudo, esta regulamentação possui exigências superficiais em diversos aspectos, inclusive, referentes à segurança e à higiene das crianças ${ }^{7,8}$. Saliente-se que a faixa etária das crianças que frequentam as escolas de educação infantil é considerada vulnerável, visto que estas possuem o sistema imunológico imaturo, não apresentam consciência de hábitos de higiene e ainda não sabem avaliar se estão em situação de perigo ou não. Destaca-se também que as escolas de educação infantil são ambientes propícios a aglomerações, a acidentes e à ocorrência de doenças infecciosas ${ }^{8}$.

A Portaria do Ministério da Saúde $n^{\circ} 321$, de 26 de maio de $1988^{7}$, apresentava os requisitos sobre projetos arquitetônicos para construção, instalação, funcionamento e estabelecia medidas de segurança para as crianças em creches, com o propósito de proporcionar condições ideais para o seu crescimento e desenvolvimento nesses ambientes. Após esta regulamentação, outras foram preconizadas, mas somente ao nível estadual.

Existe uma proposta regulatória na Agência Nacional de Vigilância Sanitária (2015/2016), ainda em análise, para atualização das exigências presentes na Portaria do MS $n^{\circ} 321 / 1988^{7}$. De acordo com esta proposta, a necessidade de uma nova legislação se dá pelo fato de que a atual regulamentação pode ser considerada superficial diante de alguns itens necessários para maior proteção da saúde das crianças da faixa etária de zero a cinco anos e 11 meses, pois ela trata em sua maior parte somente sobre estrutura física. Alguns assuntos que estão sendo revisados: necessidade de cuidados com o uso de medicamentos; necessidade de maiores orientações referentes à higiene, boas práticas na troca de fraldas, prevenção de doenças contagiosas; necessidade de treinamento dos manipuladores de alimentos sobre boas práticas sanitárias para prevenção de doenças transmitidas por alimentos; aumento de requisitos mínimos para a segurança de móveis, materiais e equipamentos que entram em contato direto com as crianças, entre outros ${ }^{8}$.

No estado do Rio Grande do Sul (RS), foi publicada a Portaria Estadual $n^{\circ} 172$, de 3 de maio de $2005^{\circ}$, que estabeleceu o regulamento técnico para licenciamento de Estabelecimentos de Educação Infantil (EEI). Ela foi promulgada após um incêndio ocorrido em uma creche na cidade de Uruguaiana (RS) no ano 2000. A creche atendia 117 crianças, sendo que 12 crianças entre dois e três anos foram vítimas fatais e a causa foi um pano de tecido caído sobre o aquecedor de uma das salas de aula, durante o horário de dormir, após o almoço. Fato que gerou mobilização para elaboração de uma nova regulamentação estadual ${ }^{10,11}$.

A Portaria Estadual $n^{\circ} 172 / 2005^{9}$ entrou em vigor em todo o estado do RS, com o objetivo de licenciar, de acordo com os aspectos da Vigilância Sanitária (Visa), todos os EEl públicos e privados, não mais os conceituando como "creches". Entre as principais exigências presentes nesta portaria para a liberação do alvará sanitário estão os aspectos relacionados com: higiene, conservação e organização dos ambientes, móveis e utensílios; profissionais mínimos necessários presentes no quadro funcional; a necessidade de um projeto arquitetônico aprovado na Visa municipal; autorização de funcionamento expedida pelo ConseIho Estadual ou Municipal de Educação, entre outros.

O Plano Nacional de Educação de 2014 (Lei n 13.005, de 25 de junho de 2014) traçou metas até o ano de 2024, com o objetivo de contemplar todas as exigências já citadas no artigo 214 da CF 1988, e alguns de seus itens são a melhoria da qualidade do 
ensino e a universalização do atendimento escolar em todo território nacional. Uma das propostas do mesmo é que, no mínimo, $50 \%$ da cobertura de atendimento de crianças com três anos de idade seja atingida. Entre os anos de 2014 a 2018, as matrículas em creches aumentaram 23,8\% e somente em 2018 o acréscimo foi de $5,3 \%{ }^{4}$.

Conforme dados do censo escolar do Instituto Nacional de Estudos e Pesquisas Educacionais Anísio Teixeira (Inep), o Brasil possui 69,7 mil creches, sendo $40,4 \%$ creches privadas e $25,0 \%$ destas conveniadas com estados e/ou municípios. Os EEI, considerando as faixas etárias de creche e pré-escola (zero a cinco anos), possuem 8,7 milhões de alunos ${ }^{12}$.

Neste contexto, foi objetivo deste estudo identificar a conformidade normativa dos estabelecimentos privados com atividade exclusiva de educação infantil, no município de Gravataí (RS).

\section{MÉTODO}

Este trabalho objetiva identificar a conformidade normativa dos estabelecimentos privados com atividade exclusiva de educação infantil no município de Gravataí quanto à presença de alvará sanitário, projeto arquitetônico aprovado na Visa municipal, cadastro no Conselho Municipal de Educação de Gravataí (CMEG), número de professores habilitados e existência de responsável técnico legalmente habilitado.

O município de Gravataí está situado na região metropolitana de Porto Alegre, capital do estado do RS, conta com uma população estimada de 281.519 habitantes para 2019, produto interno bruto (PIB) per capita de $\mathrm{R} \$ 35.740,00$, renda média de $\mathrm{R} \$ 737,29$ (2015) e índice de desenvolvimento humano (IDH) de $0,736(2010)^{13}$.

O Departamento da Vigilância em Saúde (Viemsa), da Secretaria Municipal de Saúde (SMS) de Gravataí é dividido em: Vigilância Ambiental (VIAM), Vigilância Epidemiológica (VIEP), Vigilância em Saúde do Trabalhador (Visat) e Visa. 0 setor responsável pelas vistorias aos estabelecimentos sujeitos a alvará sanitário, incluindo os EEI, é a Visa.

A Visa é dividida entre os núcleos de Alimentos, Estabelecimentos de Interesse à Saúde, Produtos de Interesse à Saúde e Arquitetura. Estes núcleos possuem profissionais de diferentes áreas, tais como: arquitetos, enfermeiros, técnicos em enfermagem, engenheiros de alimentos, médicos veterinários, nutricionistas e farmacêuticos. O núcleo responsável pelas vistorias dos EEl é o de Estabelecimentos de Interesse à Saúde. A pesquisa também foi realizada na Secretaria Municipal de Educação (SMED) e no CMEG.

O município não possui legislação própria para o licenciamento dos EEl, porém, as vistorias são norteadas pela legislação estadual ${ }^{10}$. Com relação às exigências pedagógicas, a Resolução do CMEG $\mathrm{n}^{\circ} 1$, de 6 de julho $2016^{14}$, enumera as condições para a oferta da educação infantil no Sistema Municipal de Ensino, sejam escolas públicas municipais ou privadas. Entre suas designações está a necessidade de que todas as escolas de educação infantil devem estar cadastradas e credenciadas no Sistema Municipal de Ensino e as turmas da educação infantil presentes em escolas de ensino fundamental devem, também, ter autorização de funcionamento. Além disso, esta resolução afirma a necessidade e a responsabilidade de toda escola de que todas as crianças estejam acompanhadas em todas as suas atividades de um professor devidamente habilitado para a função.

No município de Gravataí há 12 escolas municipais de educação infantil; 63 escolas municipais de ensino fundamental com atendimento de crianças na faixa etária da educação infantil; 19 escolas de educação infantil de cunho privado, porém com convênio com a administração pública municipal; e $69 \mathrm{EEl}$ privadas. A taxa de cobertura de vagas versus população estimada na faixa etária, para 2018, envolvia: 6.690 vagas disponibilizadas (sendo 1.633 de creche e 5.057 de pré-escola), com um contingente de 4.669 alunos aguardando vaga na rede municipal. Portanto, no total há 163 escolas com atendimento de crianças na faixa etária da educação infantil, entre públicas e privadas. As escolas de Ensino Fundamental e Médio foram excluídas deste estudo porque a legislação utilizada, Portaria Estadual $n^{\circ}$ 172/20059, regulamenta escolas de Educação Infantil (zero-seis anos).

As escolas públicas devem acatar as mesmas exigências legais das escolas privadas, todavia, não há a obrigatoriedade da Administração Pública de liberar tal documento regulador para si próprio (Lei Federal $n^{\circ}$ 6.437, de 24 de agosto de 1977 artigo $10^{\circ}$, inciso $\mathrm{XLI}$, parágrafo único: “Independem de licença para funcionamento os estabelecimentos integrantes da Administração Pública ou por ela instituídos [...]”. Assim, este estudo se centra exclusivamente nos 69 estabelecimentos privados registrados no município ${ }^{15}$.

Foram utilizados como fonte de dados os registros da Visa de Gravataí sobre os EEI privados, sendo estes: os processos de viabilidade e de denúncia e seus relatórios de vistoria e as planilhas de acompanhamento dos estabelecimentos. 0 período da coleta dos dados foi de janeiro de 2018 a abril de 2019.

Os dados referentes ao cadastro no CMEG, número de crianças (porte da escola) e habilitação dos professores, foram informados pela Secretaria Municipal da Educação de Gravataí. Os dados coletados correspondem às exigências presentes na Portaria Estadual $n^{\circ} 172 / 2005^{9}$ e na Resolução do CMEG $n^{\circ} 1 / 2016^{14}$, baseando-se nos principais documentos exigidos às escolas pelas Secretarias Municipais da Saúde e da Educação, visando a regularização das instituições.

As variáveis coletadas foram: alvará sanitário vigente; presença de projeto arquitetônico aprovado na Visa municipal; presença de cadastro e/ou autorização no CMEG; habilitação de professores; classificação do estabelecimento (escola) de acordo com seu porte, responsável técnico da área da saúde, sua formação técnica, e responsável nutricionista, conforme preconizado pela legislação vigente.

Com relação à habilitação dos professores, a Resolução do CMEG $n^{\circ} 1 / 2016^{14}$ e a LDB $n^{\circ} 9.394 / 1996^{5}$ definem que a formação 
mínima de professores na educação infantil seja o Curso Normal de Nível Médio (antigo magistério) ou Licenciatura Plena em Pedagogia. Sendo que, para os EEI serem devidamente cadastrados e/ou autorizados no CMEG, estes devem já estar com todos os professores habilitados.

Os EEl foram classificados segundo seu porte (número de crianças atendidas) e segundo os critérios que constam no item 2.1.5 do anexo I da Portaria Estadual $\mathrm{n}^{\circ}$ 172/2005': pequeno porte (até 50 crianças), médio porte (51 a 100 crianças) e grande porte (acima de 100 crianças).

Os dados coletados foram inseridos em uma planilha eletrônica, e a estatística descritiva foi usada para apresentação dos resultados (frequência e percentual).

O presente estudo empregou dados secundários de acesso público, não necessitando ser encaminhado para Comitê de Ética em Pesquisa. Para sua realização houve um termo de autorização emitido pela Coordenadora do Núcleo Municipal de Educação em Saúde Coletiva de Gravataí, apresentado à Escola de Administração da Universidade Federal do Rio Grande do Sul (UFRGS).

\section{RESULTADOS E DISCUSSÃO}

De acordo com os dados coletados nas Secretarias Municipais de Saúde e de Educação de Gravataí, desde janeiro de 2018 até abril de 2019, havia $69 \mathrm{EEI}$. Neste período, quatro $(5,8 \%)$ estabelecimentos foram interditadas pela Visa e cinco $(7,2 \%)$ encerraram suas atividades.

Dentre os $60 \mathrm{EEI}$ que estavam em funcionamento, oito (13,3\%) possuíam alvará sanitário vigente e cinco $(8,3 \%)$ já obtiveram alvará sanitário nos anos anteriores, todavia como tinham vencido, estavam em processo de renovação do documento (Tabela). Conforme a Portaria Estadual $n^{\circ} 172 / 2005$, o alvará sanitário tem validade de um ano a contar da data de sua concessão, sendo necessária à sua renovação anual ${ }^{9}$.

Quando finda a vigência anual do alvará sanitário, as escolas devem protocolar, na Prefeitura Municipal de Gravataí, o processo de solicitação de renovação do documento. Contudo, mesmo que conste nas legislações vigentes que os estabelecimentos sujeitos à fiscalização da Visa devem iniciar seu funcionamento após autorização do órgão sanitário competente, sabe-se que a Visa avalia cada situação individualmente, monitorando e estabelecendo prazos para que se regularizem (Informação Verbal). Vale destacar que somente não são concedidos prazos em situações de risco iminente a saúde pública.

Apenas um terço dos EEl possuía projeto arquitetônico aprovado na Visa municipal, um dos requisitos para a liberação do alvará sanitário, pois, a partir de sua aprovação, é definido o número de crianças por $\mathrm{m}^{2}$ nas salas de aula e nos ambientes de convivência. Comparando a Portaria Estadual n ${ }^{\circ}$ 172/2005

Tabela. Variáveis de conformidade das escolas privadas de educação infantil, Gravataí (RS), janeiro/2018 a abril/2019 ( $\mathrm{n}=60$ ).

\begin{tabular}{|c|c|c|}
\hline Situação das escolas de educação infantil & $\mathrm{N}$ & $\%$ \\
\hline \multicolumn{3}{|l|}{ Alvará sanitário vigente } \\
\hline Sim & 8 & 13,3 \\
\hline Não & 52 & 86,7 \\
\hline Total & 60 & 100,0 \\
\hline \multicolumn{3}{|l|}{ Alvará sanitário em renovação } \\
\hline Sim & 5 & 8,3 \\
\hline Não & 55 & 91,7 \\
\hline Total & 60 & 100,0 \\
\hline \multicolumn{3}{|l|}{ Projeto arquitetônico aprovado na Visa } \\
\hline $\operatorname{Sim}$ & 20 & 33,3 \\
\hline Não & 40 & 66,7 \\
\hline Total & 60 & 100,0 \\
\hline \multicolumn{3}{|c|}{ Escolas autorizadas e/ou cadastradas no CMEG com professores habilitados } \\
\hline Sim & 36 & 60,0 \\
\hline Não & 24 & 40,0 \\
\hline Total & 60 & 100,0 \\
\hline \multicolumn{3}{|c|}{ Responsável técnico e/ou responsável nutricionista } \\
\hline Sim & 13 & 21,7 \\
\hline Não & 47 & 78,3 \\
\hline Total & 60 & 100,0 \\
\hline
\end{tabular}

Visa: Vigilância Sanitária; CMEG: Conselho Municipal de Educação de Gravataí.

Fonte: Elaborada pelos autores, 2020. 
com a Portaria MS $n^{\circ} 321 / 1988^{7}$, a última não exige projeto arquitetônico aprovado na Visa, ou seja, a regulação estadual é mais criteriosa.

Estudo realizado para avaliar as condições das creches públicas e conveniadas com o poder público no Brasil, considerados os microdados dos censos escolares 2007 e 2014, identificou que a maioria tem como local de funcionamento um prédio próprio para escola. Todavia, existiam creches funcionando em salas de empresas, unidades prisionais, templos, casas próprias dos docentes, ranchos e galpões. Sobre as dependências da educação infantil, apenas $4,1 \%$ das mais de 12 mil creches municipais possuíam berçário e somente $12,1 \%$ apresentavam banheiro adequado para a faixa etária ${ }^{16}$.

A partir dos dados coletados, constatou-se que nove $(45,0 \%)$ das 20 escolas que estavam com projeto arquitetônico aprovado ainda não o haviam executado na íntegra e 11 (55,0\%) cumpriram as adequações conforme previstas no projeto aprovado. Destas 11 , oito estabelecimentos estavam com alvará sanitário vigente e três apresentavam pendências com outras documentações exigidas, como a certidão de cadastro do nutricionista liberada pelo Conselho Regional de Nutricionistas (CRN).

Com relação ao Cadastro e/ou autorização de funcionamento no CMEG, foi constatado que $36(60,0 \%)$ dos $60 \mathrm{EEI}$ possuíam documentação mínima na SMED, aprovada pelo CMEG. Ainda, destaca-se que esse mesmo número de escolas possuía todos os professores devidamente habilitados, seja com magistério, pedagogia ou outro curso de graduação na modalidade de licenciatura, conforme exigido na Resolução do CMEG $\mathrm{n}^{\text {* }}$ $1 / 2016^{14}$. Porém, não foi possível calcular a porcentagem dos professores com formação mínima, visto não haver essa informação na SMED.

Em um estudo realizado no município de Porto Alegre, Bruscato ${ }^{17}$ relatou o baixo percentual de escolas credenciadas no Conselho Municipal de Educação (CME). Em 2007, havia 311 escolas privadas vinculadas à $S M E$, das quais $20(6,43 \%)$ possuíam o processo de credenciamento concluído. Ressalta-se que o CME do município de Porto Alegre também exarou sua resolução com relação aos padrões mínimos para a educação infantil, semelhante ao que o CMEG realizou.

A Prefeitura Municipal de Gravataí possui um Grupo de TrabaIho Multidisciplinar instituído entre as Secretarias da Saúde, da Educação, do Desenvolvimento Econômico e Turismo e de Desenvolvimento Urbano, regularizado a partir do Decreto Municipal $n^{\circ} 13.697$, de 14 de maio de 2014 ${ }^{18}$. Este grupo tem como objetivo orientar os EEl a se regularizarem de acordo com o preconizado em todos os setores afins a este ramo de atividade, visando a diminuição das atividades punitivas ${ }^{18}$.

Quanto ao porte dos EEI, considerando os projetos aprovados e os dados quantitativos de crianças em cada escola em atividade, $47(78,3 \%)$ escolas eram de pequeno porte (até 50 crianças), $12(20 \%)$ de médio porte (51 a 100 crianças) e apenas uma $(1,7 \%)$ de grande porte, acima de 101 crianças. Em um estudo semelhante no município de Pelotas (RS) foi constatado que $86 \%$ das escolas públicas eram de médio porte e $50 \%$ dos privados possuíam até 24 crianças, ou seja, estabelecimentos de pequeno porte ${ }^{19}$.

Ainda na Tabela, $13(21,7 \%)$ EEI possuíam responsáveis técnicos e/ou nutricionistas responsáveis devidamente certificados pelo seu conselho profissional. As outras $47(78,3 \%)$ escolas possuíam o profissional nutricionista, apresentando somente o protocolo de encaminhamento da documentação para o CRN. Devido ao fato da obrigatoriedade destes dois profissionais nos EEI, mas o nutricionista ser considerado habilitado para a função de responsável técnico da área da saúde, os EEI optam em possuir em seu quadro funcional somente o nutricionista desempenhando as duas funções, conforme permitido no item 2.2.1 do anexo I da Portaria Estadual $n^{\circ} 172 / 2005^{9}$.

Nesse estudo, limitações da qualidade dos dados coletados devem-se à própria característica de suas fontes e formas de preenchimento. Sua discussão esbarrou na escassez de trabalhos semelhantes existentes na literatura. Desta forma, seu potencial de generalização é restrito.

\section{CONCLUSÕES}

O município de Gravataí, no período de janeiro de 2018 a abril de 2019 , possuía 60 estabelecimentos privados com atividade exclusiva de educação infantil ativos, $47(78,3 \%)$ de pequeno porte, sendo que apenas oito $(13,3 \%)$ com alvará sanitário vigente e cinco $(8,3 \%)$ em processo de renovação; um terço dos estabelecimentos possuía projeto arquitetônico aprovado na Visa municipal. Com relação ao cadastro e autorização junto à SME, 36 $(60,0 \%)$ estabelecimentos apresentavam documentação na SMED aprovadas pelo CME. Entretanto, apenas $13(21,7 \%)$ estabelecimentos dispunham de responsáveis técnicos ou nutricionistas devidamente certificados pelos seus conselhos.

Ao final, a maioria dos estabelecimentos não preenchia os requisitos presentes na Portaria Estadual $n^{\circ} 172 / 2005$ que regulamenta o seu licenciamento de funcionamento, o que configura um grave problema a ser enfrentado pelos gestores de saúde $e$ educação do município.

\section{REFERÊNCIAS}

1. Kuhlmann MJ, Fernandes FS. Infância: construção social e histórica. In: Vaz AF, Momm CM, organizadores. Educação infantil e sociedade: questões contemporâneas. Nova Petrópolis: Nova Harmonia; 2012. p. 21-38.
2. Moreira JAS, Lara AMB. Políticas públicas para a educação infantil no Brasil (1990-2001). Maringá: Eduem; 2012[acesso 10 jun 2019]. Disponível em: http://books.scielo.org/id/ kcv6j/pdf/moreira-9788576285854-05.pdf 
3. Ministério da Educação (BR). Política nacional de educação infantil: pelo direito das crianças de zero a seis anos à educação. Brasília: Ministério da Educação; 2003[acesso 29 maio 2019]. Disponível em: http://portal.mec.gov.br/seb/ arquivos/pdf/polinaci.pdf

4. Ministério da Educação (BR). História. Brasília: Ministério da Educação; 2019[acesso 29 maio 201]. Disponível em: http://portal.mec.gov.br/index. php?Itemid=171\&id=2\&option=com_content\&view=article

5. Brasil. Lei $N^{\circ} 9.394$, de 20 de dezembro de 1996. Estabelece as diretrizes e bases da educação nacional. Diário Oficial União. 23 dez 1996.

6. Brasil. Constituição da República Federativa do Brasil. Brasília: Senado Federal; 1988.

7. Ministério da Saúde (BR). Portaria $N^{\circ} 321$, de 26 de maio de 1988. Aprova as normas e os padrões mínimo destinados a disciplinar a construção, instalação e o funcionamento de creches em todo o território nacional, e dá outras providências. Diário Oficial União. 27 maio 1988.

8. Agência Nacional de Vigilância Sanitária -

Anvisa. Requisitos de segurança sanitária para o funcionamento dos estabelecimentos de educação infantil: proposta regulatória. Brasília: Agência Nacional de Vigilância Sanitária; 2016[acesso 24 maio 2019]. Disponível em: http://portal.anvisa.gov.br/ documents/33856/2913831/ Requisitos+de+Seguran\%C3\% A7a+Sa nit\%C3\%A1ria+para+o+fu ncionamento+dos +estabelecimentos+de+educa\%C3\%A7\%C3\%A30+infantil.pdf/ e4f839b7-e143-45cc-be46-4b2fb0a232f3

9. Secretaria do Estado da Saúde do Rio Grande do Sul - SES-RS. Portaria No 172, de 3 de maio de 2005. Estabelece o regulamento técnico para licenciamento de estabelecimentos de educação infantil. Diário Oficial do Estado. 4 maio 2005.

10. Souza CA, Gerchmann L. Incêndio em creche mata 12 crianças. Folha de S. Paulo Cotidiano. 21 jun 2000[acesso 10 maio 2019]. Disponível em: https: / /www1.folha.uol. com.br/fsp/cotidian/ff2106200028.htm

11. Expresso da Notícia. Funcionária de creche é condenada pela morte de 12 crianças. Jusbrasil. 2002[acesso $25 \mathrm{abr}$ 2019]. Disponível em: https://expresso-noticia.jusbrasil. com.br/noticias/5382/funcionaria-de-creche-e-condenadapela-morte-de-12-criancas

12. Instituto Nacional de Estudos e Pesquisas Educacionais Anísio Teixeira - Inep. Dados do censo escolar 2014 a 2018. Brasília: Instituto Nacional de Estudos e Pesquisas Educacionais Anísio Teixeira; 2018[acesso 25 abr 2019]. Disponível em: http://portal.inep.gov.br/artigo/-/asset_ publisher/B4AQV9zFY7Bv/content/dados-do-censo-escolarnumero-de-matriculas-na-educacao-infantil-cresceu-11-1de-2014-a-2018/21206

13. Instituto Brasileiro de Geografia e Estatística - IBGE. Cidades e estados: Gravataí. Brasília: Instituto Brasileiro de Geografia e Estatística; 2019[acesso 11 ago 2020]. Disponível em: https://www.ibge.gov.br/cidades-eestados/rs/gravatai.html

14. Conselho Municipal de Educação de Gravataí - CMEG. Resolução $N^{0}$ 1, de 6 de julho de 2016. Estabelece condições para a oferta da educação infantil no sistema municipal de ensino de Gravataí. Diário Oficial do Município. 7 jul 2016.

15. Brasil. Lei № 6.437, de 20 de agosto de 1977. Configura infrações à legislação sanitária federal, estabelece as sanções respectivas, e dá outras providências. Diário Oficial União. 24 ago 1977.

16. Oliveira TG. As condições das creches públicas e conveniadas com o poder público no Brasil. Rev Iberoam Educ. 2016;71:63-86. https://doi.org/10.35362/rie7104

17. Bruscato $A C M$. A regulamentação não regulada das instituições de educação infantil particulares no município de Porto Alegre. Porto Alegre: Universidade Federal do Rio Grande do Sul, 2008.

18. Município de Gravataí. Decreto municipal № 13.697 , de 14 de maio de 2014. Cria o departamento multidisciplinar de educação infantil de Gravataí. Diário Oficial do Municipio. 15 maio 2016.

19. Barros AJD, Gonçalves EV, Borba CRS, Lorenzatto CS, Motta DB, Silva VRL et al. Perfil das creches de uma cidade brasileira de porte médio do sul do Brasil: operação, cuidados, estrutura física e segurança. Cad Saúde Pública. 1999;15(3):597-604. https://doi.org/10.1590/S0102-311X1999000300017

Contribuição dos Autores

Teixeira SC, Silva PS - Concepção, planejamento (desenho do estudo), aquisição, análise, interpretação dos dados e redação do trabalho. Bordin R - Aquisição, interpretação dos dados e redação do trabalho. Todos os autores aprovaram a versão final do trabalho.

Os autores informam não haver qualquer potencial conflito de interesse com pares e instituições, políticos ou financeiros deste estudo.

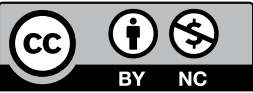

Licença CC BY-NC atribuição não comercial. Com essa licença é permitido acessar, baixar (download), copiar, imprimir, compartilhar, reutilizar e distribuir os artigos, desde que para uso não comercial e com a citação da fonte, conferindo os devidos créditos de autoria e menção à Visa em Debate. Nesses casos, nenhuma permissão é necessária por parte dos autores ou dos editores. 